\title{
REDISTRIBUTION OF RESIDUAL WELDING STRESSES IN IN-VESSEL CORE BARREL OF WWER-1000 REACTOR DURING OPERATION
}

\author{
O.V. MAKHNENKO, E.A. VELIKOIVANENKO and I.V. MIRZOV \\ E.O. Paton Electric Welding Institute, NASU \\ 11 Bozhenko Str., 03680, Kiev, Ukraine. E-mail: office@paton.kiev.ua
}

\begin{abstract}
Reactor baffle is subjected to high radiation doses that results in its swelling and change of form in operation. Inside pressure of baffle on core barrel creates additional stresses in zone of contact. Residual welding stresses can also significantly effect a level of stressed state of core barrel wall, that should be considered in estimation of working capacity of vessel internals for extension of WWER-1000 reactor service life. Thus, a relevant task is an estimation of stressed state of in-vessel core barrel in area of its contact with baffle, in particular, when place of contact coincides with welded joint zone. Aim of present work is an investigation of stressed state in zone of welds of in-vessel core barrel of WWER-1000 reactor during operation considering radiation swelling and contact interaction of baffle and core barrel. A problem was solved by $2 \mathrm{D}$ finite element method using current mathematical models of radiation swelling and change of mechanical properties of $08 \mathrm{Kh} 18 \mathrm{~N} 10 \mathrm{~T}$ steel. Calculations show that effect of only temperature deformation does not promote high stresses in the core barrel wall, but degree of stress redistribution in it due to radiation swelling depends on residual welding stresses. Circumferential and axial stresses, caused by contact interaction of core barrel with baffle, have the largest impact on stressed state of the in-vessel core barrel wall in course of 60 years of operation. Stresses in the in-vessel core barrel welds at the end of extended operation period (60 years) are close to the values of yield strength of irradiated material. Residual welding stresses can significantly effect the level of stressed state of the core barrel wall, that should be considered in estimation of working capacity of vessel internals at extension of service life of WWER-1000 reactor. 4 Ref., 2 Tables, 11 Figures.
\end{abstract}

Key words: in-vessel core barrel, WWER-1000 reactor, vessel internals, residual welding stresses, irradiation, 08Kh18N10T steel, life extension

In-vessel core barrel of WWER-1000 reactor is a welded cylinder structure manufactured from austenite steel 08Kh18N10T. Location of the core barrel in reactor vessel and its drawing are given in Figure 1. In-vessel core barrel has external radius $1805 \mathrm{~mm}$ and wall thickness $60 \mathrm{~mm}$ at the level of setting of core baffle.

Reactor baffle is subjected to high radiation doses, that results in its swelling and change of form in operation. Gap between baffle rings and core barrel makes $2.5 \mathrm{~mm}$ under initial condition. Contact of baffle and in-vessel core barrel during operation should be taken into account based on calculation results [1]. Inside pressure of baffle on core barrel creates additional stresses in zone of contact. Residual welding stresses can also significantly effect a level of stressed state of a core barrel wall, that should be considered in estimation of working capacity of vessel internals (VI) for extension of WWER-1000 reactor service life. Thus, estimation of stressed state of the in-vessel core barrel in area of its contact with baffle, in particular, when place of contact coincides with welded joint zone, is a relevant task. It is necessary to note that the core barrel wall is also subjected to radiation swelling, however, damaging dose is an order of magnitude less than that in the baffle.

Aim of present work is investigation of stressed state in zone of the welds of in-vessel core barrel of WWER-1000 reactor during operation considering radiation swelling and contact interaction of baffle and core barrel.

Initially, this problem was studied in work [2]. Present study improves mathematical models of radiation swelling and mechanical properties of VI material, specifies values of volumetric heat generation and damaging dose in the core barrel, develops numerical model for calculation of stress-strain state in contact of baffle and core barrel as well as simulates residual welding stresses in the welds of in-vessel core barrel.

Procedure of investigations. Series of problems was solved for achievement of stated aim. Initially, the core barrel was considered in a free state without consideration of its contact with baffle. It was done in order to understand in what way operating temperature fields and ra- 
diation swelling effect its stressed state. Contact with baffle is taken into account in the second problem. The two following problems are similar to the first ones, but they study the core barrel with residual welding stresses, which have simplified distribution.

Solving of these problems provides for understanding of redistribution of residual welding stresses in the core barrel and the way they are summarized with stresses from contact interaction of baffle and core barrel. The latter problem includes the whole experience of pervious problems, but it considers the real residual welding stress fields, obtained in course of separate numerical calculation, in the core barrel.

All problems were solved using 2D finite element method under condition of generalized plane deformation. VI material is $08 \mathrm{Kh} 18 \mathrm{~N} 10 \mathrm{~T}$ steel. Perfect plasticity model was used. Problem of estimation of stress-strain state under condition of radiation creep with swelling is solved at recalculation of stresses and deformations in each step of tracing. Heat exchange between baffle and core barrel is not considered during contact. Their contact interaction influences the stressed state of core barrel as well as baffle, both VI are simultaneously simulated with initial $2.5 \mathrm{~mm}$ gap. Internal pressure in reactor vessel is $16 \mathrm{MPa}$.

Stopping of heavy particles in VI metal promotes material heating-up. Capacity of volumetric heat generation in the core barrel is linearly changed from 5.0 (on inner surface) to $0.5 \mathrm{~W} / \mathrm{cm}^{3}$ (on outer one). Rate of accumulation of damaging dose in the core barrel is also linearly changed from 0.2 (on inner surface) to $0.02 \mathrm{dpa} /$ year (on outer one). Thermophysical properties of $08 \mathrm{Kh} 18 \mathrm{~N} 10 \mathrm{~T}$ steel are given in Table 1, and can be applied to base metal as well as weld metal. Poisson's ratio $v=0.3$.

Mechanical properties of $08 \mathrm{Kh} 18 \mathrm{~N} 10 \mathrm{~T}$ base metal and welds depend on temperature and radiation dose and are described in [3]. A model, given below, describes change of mechanical

Table 1. Thermal-physical properties of 08Kh18N10T steel [1]

\begin{tabular}{||c|c|c|c|c|c||}
\hline \hline$T,{ }^{\circ} \mathrm{C}$ & $E, \mathrm{GPa}$ & $\begin{array}{c}\alpha^{t} \cdot 10^{-6}, \\
\mathrm{~K}^{-1}\end{array}$ & $\begin{array}{c}\lambda, \\
\mathrm{W} \cdot \mathrm{m}^{-1} \cdot \mathrm{K}^{-1}\end{array}$ & $\begin{array}{c}c_{p}, \\
\mathrm{~J} \cdot \mathrm{kg}^{-1} \cdot \mathrm{K}^{-1}\end{array}$ & $\rho, \mathrm{kg} / \mathrm{m}^{3}$ \\
\hline 20 & 205 & 16.2 & 16.6 & 478 & 7900 \\
\hline 100 & 200 & 16.6 & 17.2 & 495 & 7862 \\
\hline 200 & 190 & 17.0 & 18.0 & 516 & 7821 \\
\hline 300 & 180 & 17.4 & 18.7 & 537 & 7778 \\
\hline 400 & 170 & 17.8 & 19.4 & 558 & 7732 \\
\hline 500 & 165 & 18.2 & 20.1 & 579 & 7684 \\
\hline 600 & 160 & 18.5 & 20.8 & 600 & 7634 \\
\hline
\end{tabular}
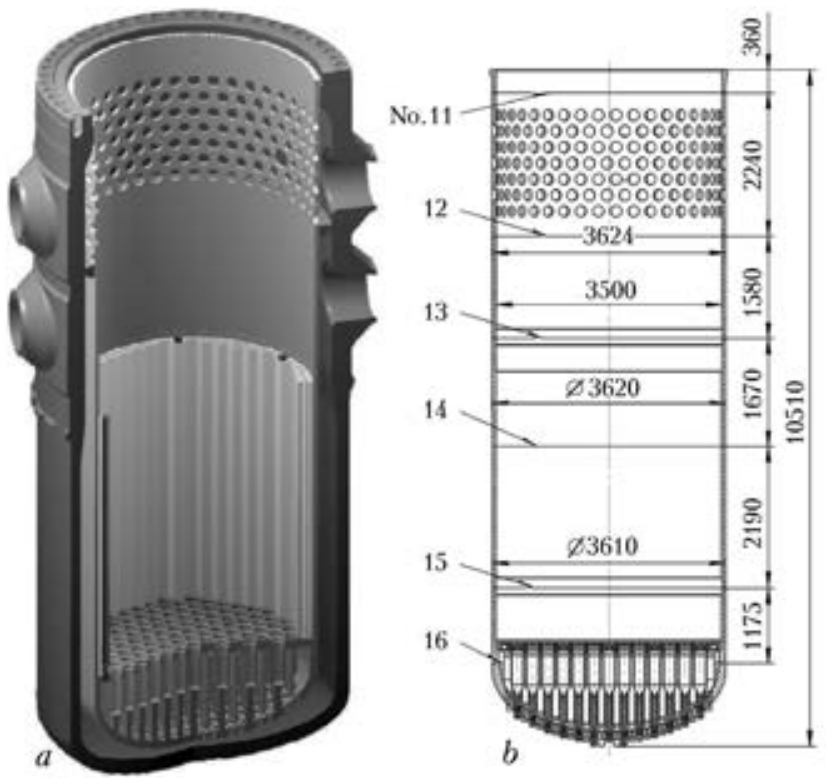

Figure 1. Location of in-vessel core barrel in structure of WWER-1000 reactor $(a)$ and its drawing $(b)$

properties of $08 \mathrm{Kh} 18 \mathrm{~N} 10 \mathrm{~T}$ steel depending on temperature and damaging dose.

Base metal yield strength

$$
\begin{gathered}
\sigma_{0.2}(T, D)=\left\{\begin{array}{l}
\sigma_{0.2}^{0}(T)+\Delta \sigma_{0.2}^{\mathrm{y}}(T, D), D<D^{*}, \\
\sigma_{0.2}^{*}(T)+\Delta \sigma_{0.2}^{*}(T, D), D \geq D^{*},
\end{array}\right. \\
\sigma_{0.2}^{0}(T)=155+239 \exp \left(-2.22 \cdot 10^{-3}(T+273)\right)(\mathrm{MPa}), \\
\Delta \sigma_{0.2}^{\mathrm{y}}(T, D)=\left(\sigma_{0.2}^{*}(T)-\sigma_{0.2}^{0}(T)\right) \times \\
\times \frac{\sqrt{1-\exp \left(-C_{\sigma_{0.2}} D\right)}}{\sqrt{1-\exp \left(-C_{\sigma_{0.2}} D^{*}\right)}}, \\
\sigma_{0.2}^{*}(T)=650+1405 \exp \left(-5.9 \cdot 10^{-3}(T+273)\right)(\mathrm{MPa}), \\
\times\left(\sqrt{1-\exp \left(-C_{\sigma_{0.2}}^{*} D\right)}-(D)=A_{\sigma_{0.2}} \times\right. \\
\left.D^{*}=7 \mathrm{dpa}, \quad C_{\sigma_{0.2}}=0.126 \mathrm{dpa}^{-1}, \quad A_{\sigma_{0.2}}=621 \mathrm{MPa}\left(-C_{\sigma_{0.2}} D^{*}\right)\right),
\end{gathered}
$$

Weld metal yield strength

$$
\begin{gathered}
\sigma_{0.2}(T, D)=\sigma_{0.2}^{0}(T)+\Delta \sigma_{Y G}(D)(\mathrm{MPa}) \\
\sigma_{0.2}^{0}(T)=255+420 \exp \left(-2.22 \cdot 10^{-3}(T+273)\right)(\mathrm{MPa}) \\
\Delta \sigma_{Y G}(D)=498 \sqrt{1-\exp (-0.3 D)}(\mathrm{MPa})
\end{gathered}
$$

Base metal tensile strength

Table 2. Temperature of heat carrier and coefficient of heat transfer for different surfaces of core barrel [1]

\begin{tabular}{|c|c|c|}
\hline Core barrel surface & $\begin{array}{c}\text { Temperature on } \\
\text { surface, }{ }^{\circ} \mathrm{C}\end{array}$ & $\begin{array}{c}\text { Coefficient of heat } \\
\text { transfer, } \mathrm{W} /\left(\mathrm{m}^{2} \cdot \mathrm{K}\right)\end{array}$ \\
\hline Outer & 291.7 & 15,900 \\
\hline Inner & 320.0 & 39,017 \\
\hline
\end{tabular}




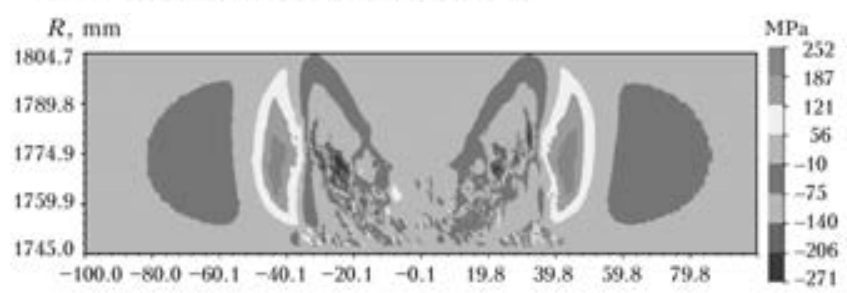

a

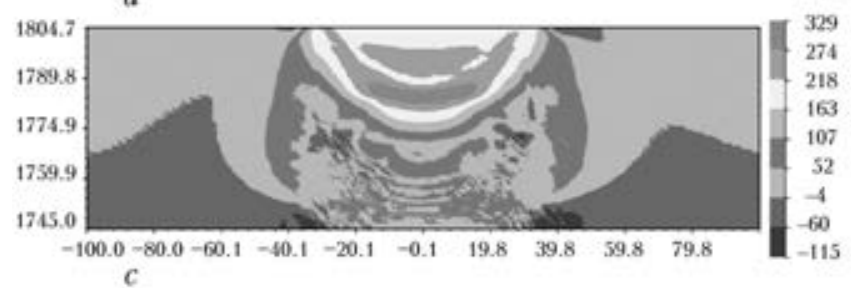

$R, \mathrm{~mm}$

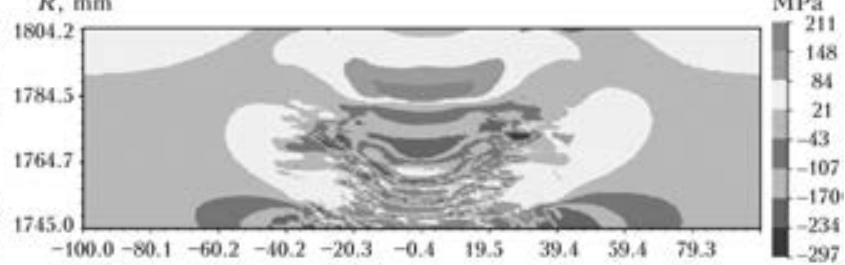

b

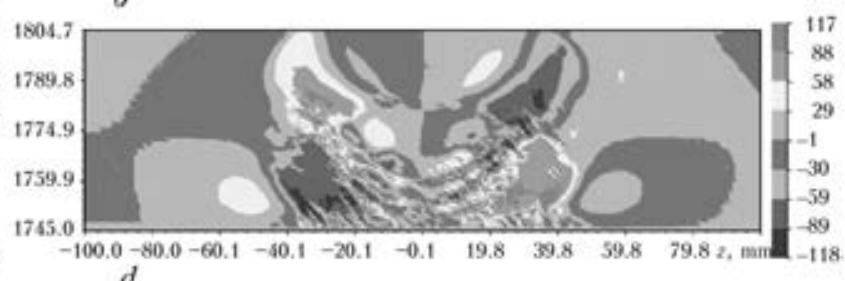

Figure 2. Residual welding stresses in core barrel of WWER-1000 reactor in cylindrical coordinates $a-\sigma_{r r} ; b-\sigma_{\beta \beta}$; $c-\sigma_{z z} ; d-\sigma_{r \beta}$

$$
\begin{gathered}
\sigma_{\mathrm{t}}(T, D)=\sigma_{\mathrm{t}}^{0}(T)+\Delta \sigma_{\mathrm{t}}(D)(\mathrm{MPa}) \\
\sigma_{\mathrm{t}}^{0}(T)=350+247 \exp \left(-6.6 \cdot 10^{-3} T\right)(\mathrm{MPa}), \\
\Delta \sigma_{\mathrm{t}}(D)=483 \sqrt{1-\exp (-0.11 D)}(\mathrm{MPa})
\end{gathered}
$$

Weld metal tensile strength

$$
\begin{gathered}
\sigma_{\mathrm{t}}(T, D)=\sigma_{\mathrm{t}}^{0}(T)+\Delta \sigma_{\mathrm{t}}(D)(\mathrm{MPa}) \\
\sigma_{\mathrm{t}}^{0}(T)=439+222 \exp \left(-9.74 \cdot 10^{-3} T\right)(\mathrm{MPa}) \\
\Delta \sigma_{\mathrm{t}}(D)=440 \sqrt{1-\exp (-0.25 D)}(\mathrm{MPa})
\end{gathered}
$$

Temperature problem with boundary conditions of the third kind was solved for estimation of stationary temperature in the wall of in-vessel core barrel. Table 2 gives heat carrier temperature and values of coefficients of heat transfer for different surfaces of the core barrel.

Numerical calculation of volumetric deformations of swelling was carried out in accordance with [4]. This mathematical model considers dependence of swelling on radiation dose, temperature, type of stressed state, values of stresses and radiation creep. The main relationships and $\mathrm{pa}^{-}$ rameters of this model are given below:

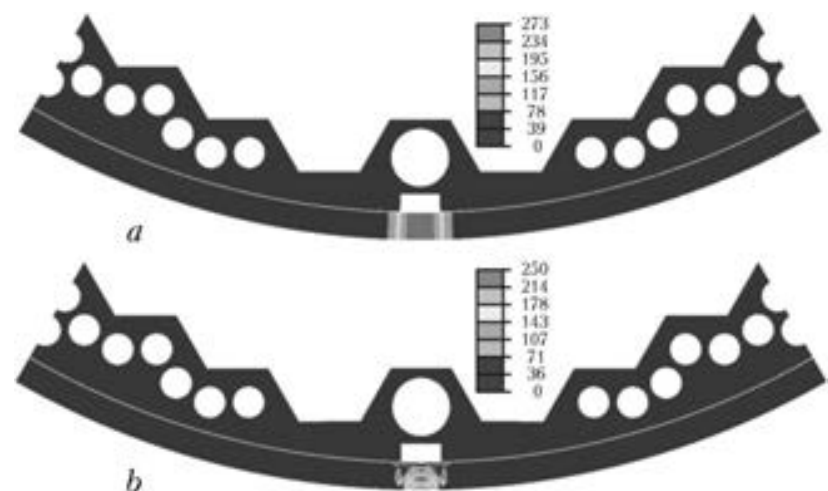

Figure 3. Intensity of stresses ( $\mathrm{MPa}$ ) in longitudinal weld of core barrel under initial condition: $a-$ simplified task; $b-$ simulated residual welding stresses

$$
\begin{gathered}
\frac{d \varepsilon_{e q}^{c}}{d t}=\left(B_{0} \frac{d D}{d t}+\omega \frac{d S}{d t}\right) \sigma_{e q}, d \varepsilon_{e q}^{c}>0,\left.\varepsilon_{e q}^{c}\right|_{t=0}=0, \\
\frac{d S}{d t}=C_{D} n D_{i}^{n-1} f_{0}(T) f_{1}\left(\sigma_{m}\right) f_{3}(\kappa) d D, d S>0,\left.S\right|_{t=0}=0 ; \\
f_{0}(T)=\exp \left(-r\left(T-T_{\max }\right)^{2}\right), \\
f_{1}(\sigma)=1+8 \cdot 10^{-3}\left(0.85 \sigma_{m}+0.15 \sigma_{e q}\right), f_{3}(\kappa)=\exp (-\eta \kappa) ; \\
B_{0}=10^{-6} \mathrm{dpa}^{-1}, \quad \omega=2.95 \cdot 10^{-3} \mathrm{MPa}^{-1}, \\
C_{D}=1.035 \cdot 10^{-4} \mathrm{dpa}^{-n}, n=1.88, r=1.825 \cdot 10^{-4}{ }^{\circ} \mathrm{C}^{-2}, \\
T_{\max }=470{ }^{\circ} \mathrm{C}, P=4 \cdot 10^{-1} \mathrm{MPa}, \eta=8.75,
\end{gathered}
$$

where $S$ is the swelling; $D$ is the damaging dose; $\sigma_{m}$ is the medium stress; $\kappa$ is the Odqvist parameter.

Fields of residual welding stresses in the core barrel were received by calculation method using WeldPredictions software, developed the PWI staff. Simulation of longitudinal multi-pass welded joint (six passes) of cylindrical shell with inside diameter $D_{\text {in }}=3490 \mathrm{~mm}, \delta=60 \mathrm{~mm}$ thickness and $30^{\circ}$ grooving for the following mode: $I=200 \mathrm{~A}, U=17 \mathrm{~V}, v_{\mathrm{w}}=3 \mathrm{~mm} / \mathrm{s}$ (heat input $Q_{\mathrm{h}}=850 \mathrm{~J} / \mathrm{mm}$, efficiency rate 0.75 ), was carried out. Boundary problem of determination of kinetics of stress-strain state was solved in cylindrical coordinates using FEM (size of element $1 \times 1 \mathrm{~mm}$ ) by means of sequential tracing of elasto-plastic deformations from beginning of welding of the first pass to cooling after the sixth pass considering Mises yield criterion. Figure 2 shows the results of calculation of residual stress fields.

Vertical weld, located based on conservative assumptions in the contact area of baffle to core barrel (Figure 3), was investigated in this case.

Residual welding stresses for simplified problems contain only axial component. Stress in the core barrel reduces from 270 to $0 \mathrm{MPa}$ moving 


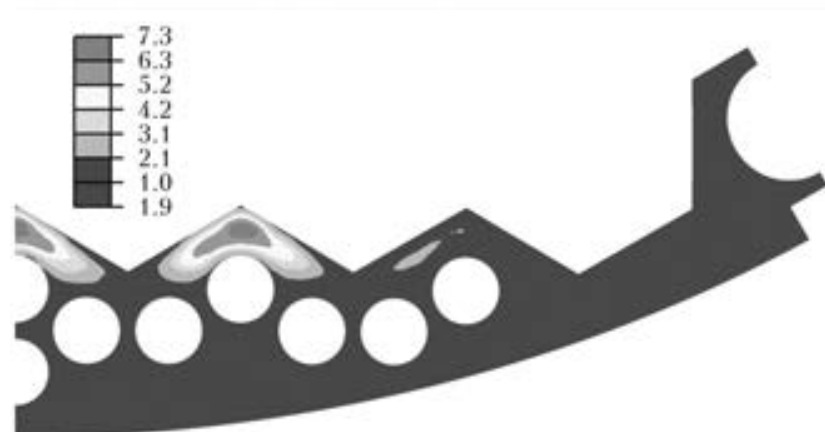

Figure 4. Field of volumetric deformations of baffle swelling after 60 years of reactor operation (calculation was carried out considering radiation creep [4])

away from center of baffle large channel in circumferential coordinate (Figure 3, $a$ ).

Results and discussion. Figure 4 shows a field of volumetric deformations of baffle swelling after 60 years of reactor operation. The baffle is deformed in radial direction due to non-uniform swelling. Radial movements are maximum in area of large channel. The same area influences the in-vessel core barrel at it contact with baffle.

Temperature distribution over thickness of the core barrel wall in mode of reactor normal operation (NO) for problems $1-5$ is shown in Figure 5 . The core barrel is heated due to stopping in metal of heavy particles, and inner and outer surfaces of the core barrel are water-cooled, therefore, temperature maximum is found inside the wall and makes $306{ }^{\circ} \mathrm{C}$. Temperature on internal and external surfaces is virtually the same and makes $290{ }^{\circ} \mathrm{C}$. Yield strength of weld metal in the core barrel under the effect of irradiation in a course of 60 years of operation was set at the level of 850 (on inner surface) and $500 \mathrm{MPa}$ (on outer one) and being linearly changed over thickness. In-vessel core barrel has cylindrical form, therefore, stress-strain state of VI will be considered in cylindrical coordinates, axis of which is co-directional with core barrel axis.

1. Core barrel in free state: heating, irradiation and cooling. Non-uniform heating promotes appearance of stresses in the core barrel wall. Quality redistributions of circumferential and axial stresses are close, therefore, only axial stresses $S_{z}$ appearing during operation will be given (Figure 6). Radial stresses are virtually constant over wall thickness and make $16 \mathrm{MPa}$, which is caused by internal pressure in the reactor.

Since temperature on inner and outer surfaces of the core barrel wall is lower than in internal area, stresses on the surfaces are tensile ones $\left(\mathrm{Fi}^{-}\right.$ gure 6 , curve 2) and compression is observed inside the wall. Irradiation during reactor operation promotes swelling of material on inner surface of core barrel wall $(\sim 0.01 \%)$, that reduces

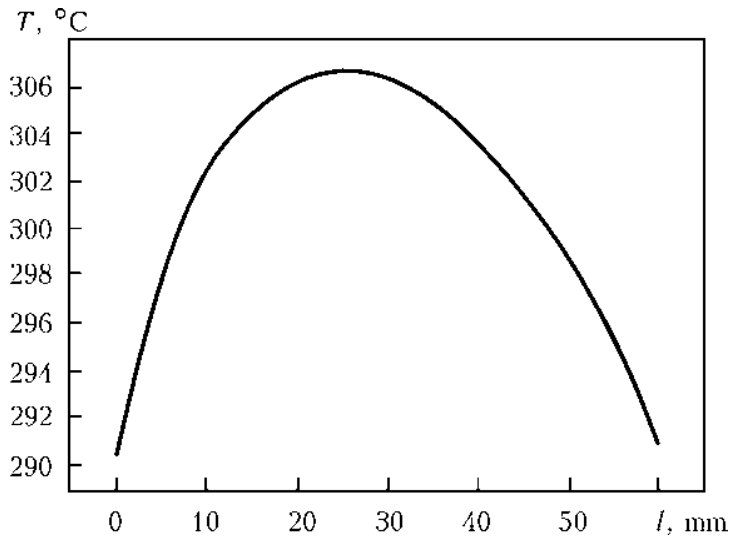

Figure 5. Distribution of temperature over thickness of core barrel wall in mode of reactor NO (hereinafter $l$ - distance from inner surface of core barrel wall)

tensile stresses in this area (Figure 6, curves 3 and 4). Based on equilibrium condition, tensile stresses on outer surface show insignificant increase. Shutdown of reactor at the end of operation period removes temperature deformations, however, redistribution of stresses, promoted by radiation swelling of material, is preserved $\left(\mathrm{Fi}^{-}\right.$ gure 6, curve 5).

Thus, radiation swelling of material of the core barrel wall promotes $10 \mathrm{MPa}$ reduction of stresses on inner surface, that based on equilibrium condition is accompanied by their insignificant growth on outer surface of the core barrel wall. Temperature deformations in the core barrel wall provoke stresses at the level of $\pm 30 \mathrm{MPa}$.

2. Contact of core barrel with baffle: heating, irradiation and cooling. Effect of radiation on the baffle promotes its swelling, that results in change of its form and contact with the core barrel after 25th year of operation (in «hot» state). Figure 7 shows redistribution of circumferential and axial stresses in the reactor core barrel during operation considering contact with the baffle. Values of stresses were taken along

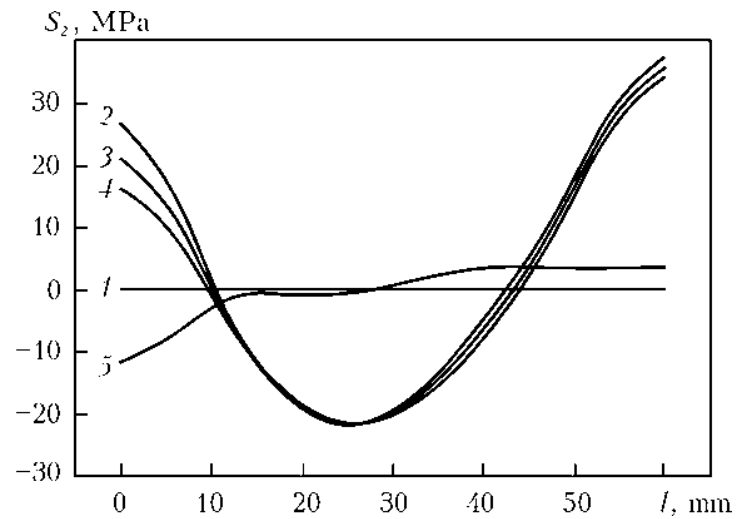

Figure 6. Redistribution of axial stresses over thickness of reactor core barrel wall during operation: hereinafter 1 initial condition; 2 - reaching of NO mode; 3,4 - after 30 and 60 years of irradiation, respectively; 5 - shutdown of reactor after 60 years 

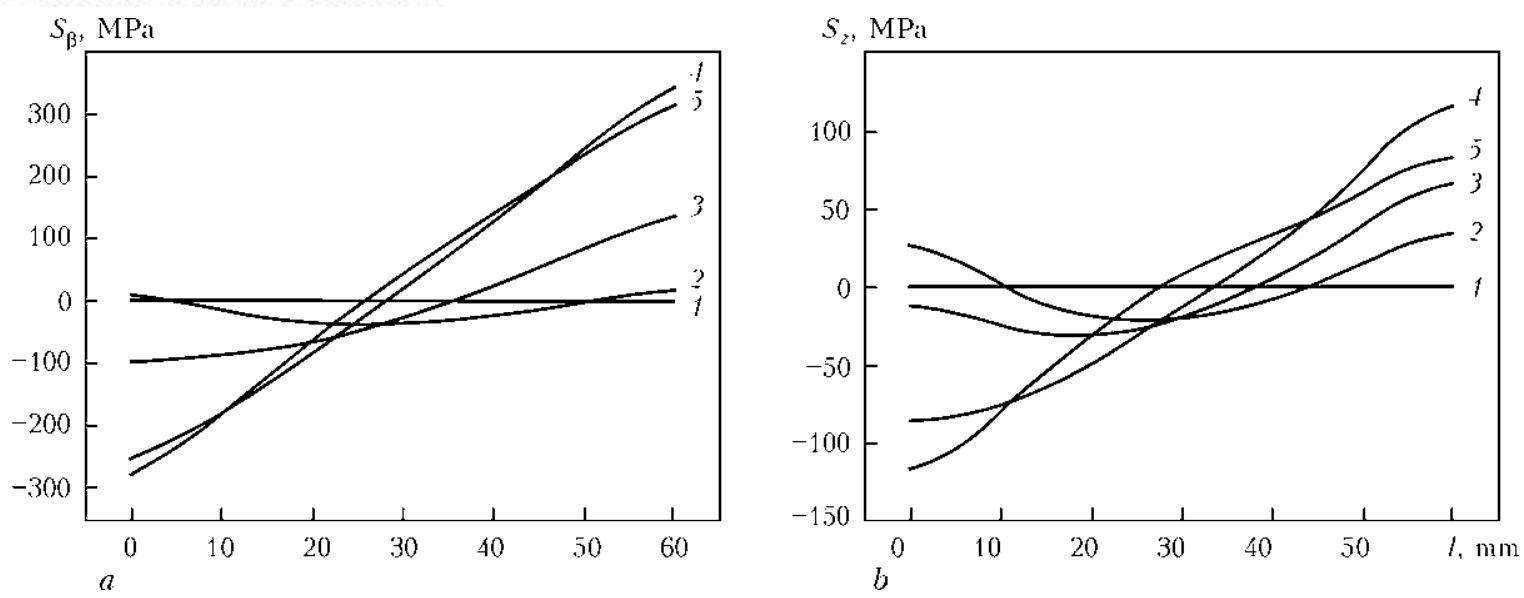

Figure 7. Redistribution of circumferential $(a)$ and axial $(b)$ stresses over thickness of reactor core barrel wall during operation considering contact with baffle

core barrel thickness in area of contact with the baffle. Curves 3-5 represent that internal pressure of baffle on core barrel wall promotes appearance of compressive circumferential and axial stresses on inner surface, as well as growth of tensile circumferential and axial stresses on outer surface of the core barrel.

Pressure of baffle on core barrel does not provoke significant rise of radial stresses. Compressive and tensile circumferential stresses are significantly larger than corresponding axial ones, and after 60 years of reactor operation they achieve $-280 \mathrm{MPa}$ (compression) on inner surface of the core barrel and $+340 \mathrm{MPa}$ (tension) on outer one. At the same time, axial stresses on inner surface of the core barrel wall make -110 and on outer one $+100 \mathrm{MPa}$.

3. Simplified welded joint. Core barrel in free state: heating, irradiation and cooling. Understanding of redistribution of compressive and tensile residual welding stresses in the core barrel during reactor operation was received by means of solving of two problems, in which the residual welding stresses in simplified welds had different signs. Redistribution of simplified residual weld-
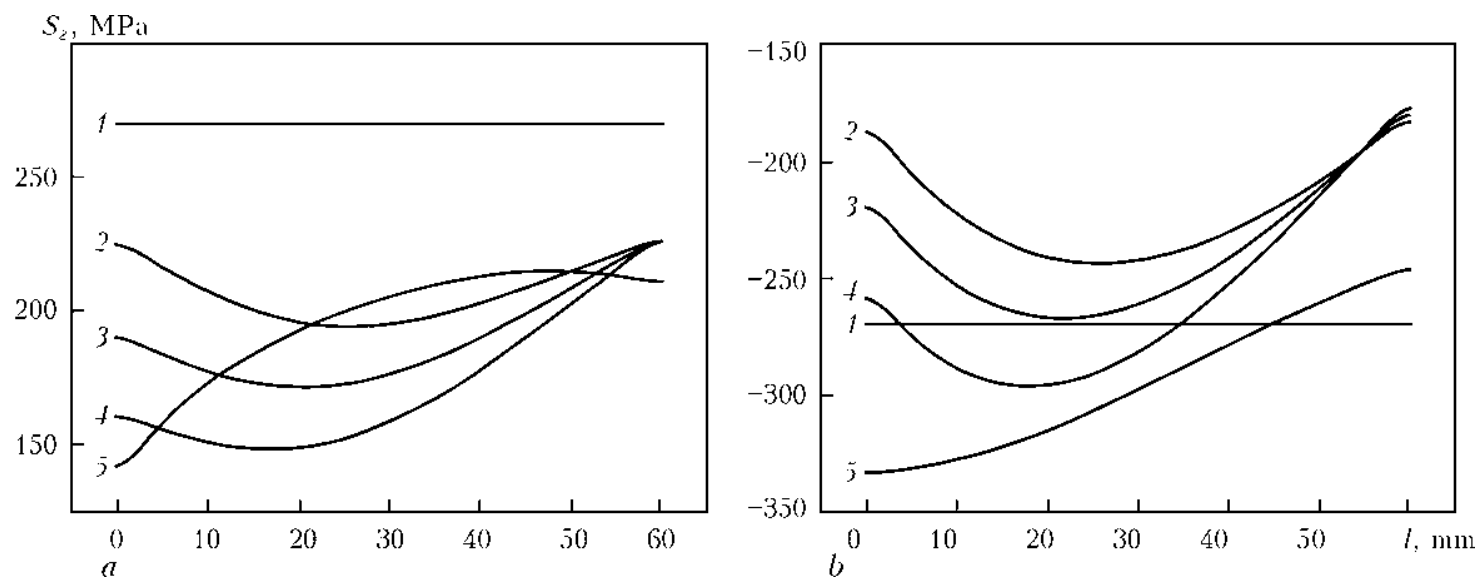

Figure 8. Redistribution of simplified residual welding stresses over thickness of reactor core barrel wall during operation: $a$ - tensile; $b$ - compressive axial stresses

ing stresses in the reactor core barrel during operation is shown in Figure 8. Reduction (relaxation) of tensile axial residual welding stresses in Figure 8, $a$ during reactor operation is explained by swelling of material close to inner surface of the core barrel wall. This is also the reason why compressive axial residual welding stresses rise on absolute value (Figure $8, b$ ). In this problem the level of effect of swelling deformations on stresses is significantly higher than in the case of absence of welded joint in the core barrel wall (problem 1). This is explained by dependence of swelling on stressed state. Tensile axial stresses in the core barrel wall reduced by $125 \mathrm{MPa}$ on inner surface and by $60 \mathrm{MPa}$ on outer one during 60 years of operation. At the same time, compressive axial stresses grew by $85 \mathrm{MPa}$ on inner surface and reduced by $20 \mathrm{MPa}$ on outer surface of the core barrel.

4. Simplified welded joint. Contact of core barrel with baffle: heating, irradiation and cooling. Consideration, the same as in problem 3, is given to redistribution of tensile (Figure 9, $a$ ) and compressive (Figure 9, $b$ ) simplified residual welding stresses in the core barrel during reactor 

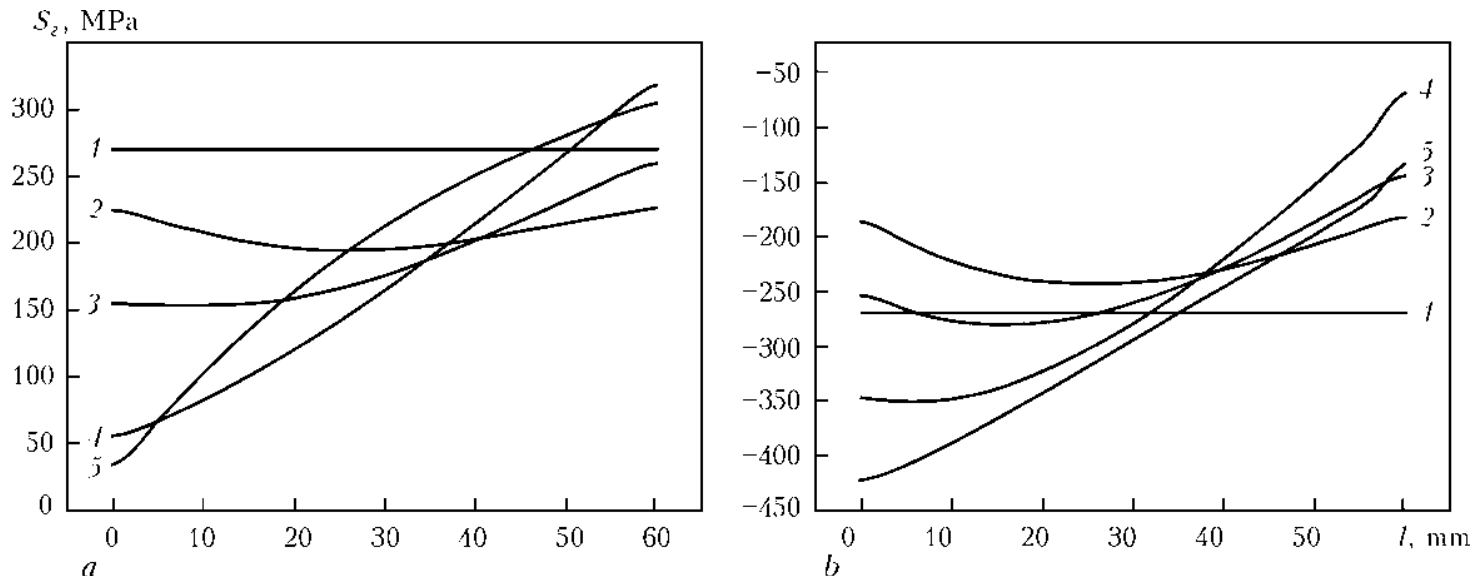

Figure 9. Redistribution of simplified residual welding stresses over thickness of reactor core barrel wall during operation considering baffle pressure: $a$ - tensile; $b$ - compressive axial stresses
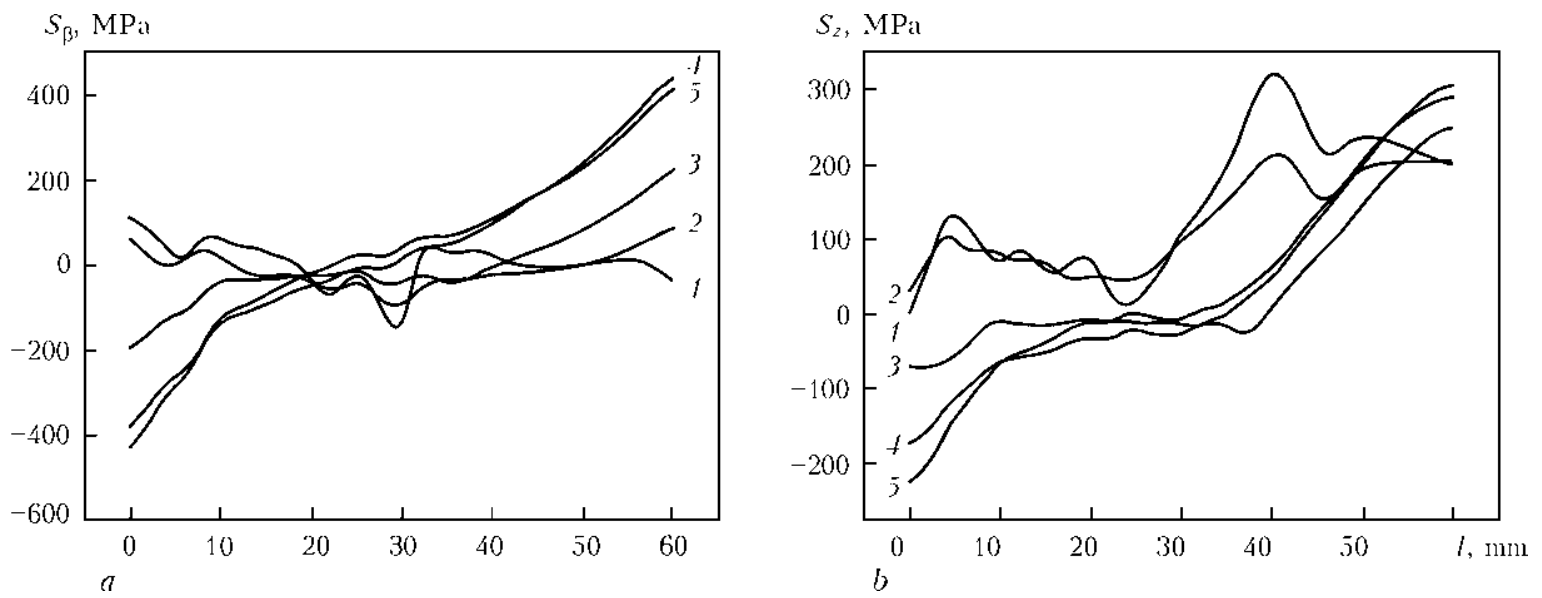

Figure 10. Redistribution of circumferential $(a)$ and axial $(b)$ stresses in zone of simplified weld of in-vessel core barrel of reactor during operation considering contact with baffle

operation. Contact interaction of in-vessel core barrel with baffle is considered in this problem. This problem is virtually a superposition of problems 2 and 3 and change of stressed state can be estimated based on their solving. Tensile axial stresses (see Figure 9, $a$ ) on inner surface reduce by $125+110=235 \mathrm{MPa}$ as a result of radiation swelling and pressure of baffle, and on outer surface they increase by $-60+100=40 \mathrm{MPa}$. Compressive axial stresses on inner surface (see Figure $9, b$ ) rise by $85+110=195 \mathrm{MPa}$ due to radiation swelling and pressure of baffle, and they decrease by $20+100=120 \mathrm{MPa}$ on outer surface of the core barrel.

5. Contact with baffle: heating, irradiation and cooling. Stress behavior in weld. Redistribution of simulated residual welding axial and circumferential stresses in the reactor core barrel during operation is shown in Figure 10. Contact with baffle is considered. Axial and circumferential stresses are the maximum ones for the invessel core barrel weld after 60 years of reactor operation, that are caused by baffle pressure. Figure 11 shows their redistribution.

Pressure of baffle on core barrel, similar as in problems 2 and 4, promotes growth of compressive circumferential and axial stresses on inner surface of the core barrel and tensile circumferential and axial stresses on outer surface (see Figure 10).
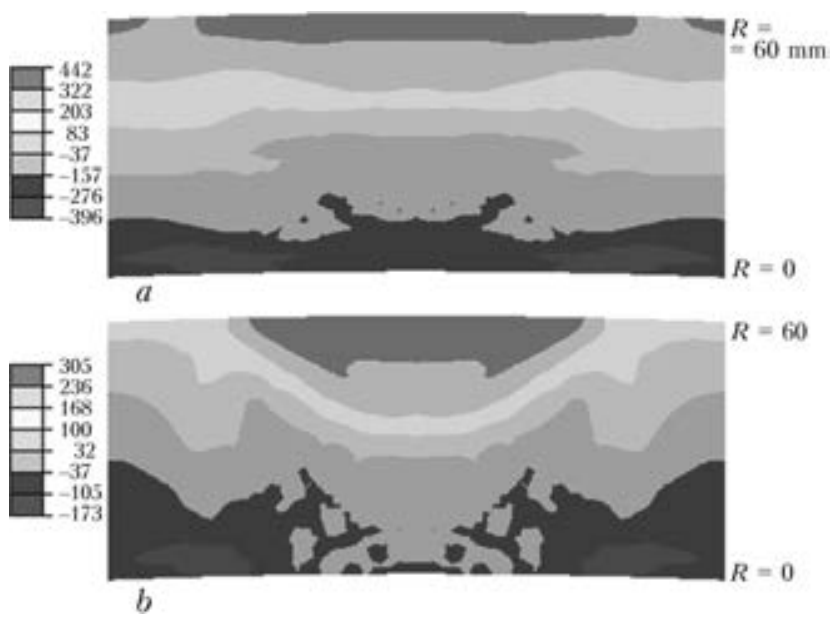

Figure 11. Distribution of circumferential ( $a$ ) and axial (b) stresses $(\mathrm{MPa})$ in zone of weld on in-vessel core barrel of reactor at the end of extended service life (60 years) considering contact with baffle 
Circumferential stresses in weld zone achieve the values (440 MPa) close to yield strength of irradiated material of the core barrel wall ( $\mathrm{Fi}^{-}$ gure $11, a$ ).

\section{Conclusions}

1. Stresses of $\pm 30 \mathrm{MPa}$ level appear in the core barrel wall as a result of temperature deformations in reaching of $\mathrm{NO}$ mode of reactor.

2. Radiation swelling without consideration of residual welding stresses for 60 years of operation promotes change of stresses in $\pm 10 \mathrm{MPa}$ limits.

3. Redistribution of stresses due to radiation swelling in zone of the welded joints on core barrel wall depends on level of residual welding stresses. Reduction of residual tensile stresses can achieve $125 \mathrm{MPa}$.

4. Contact interaction of core barrel with baffle can make the largest (up to $340 \mathrm{MPa}$ ) impact in stressed state of the in-vessel core barrel in course of 60 years of operation.

5. Circumferential stresses in zone of welds of the in-vessel core barrel at the end of extended operation period (60 years) considering residual welding stresses and contact with baffle can reach high values (440 MPa) close to yield strength of irradiated material.

6. Residual welding stresses can significantly effect the level of stressed state of the core barrel wall, that is necessary to be considered in estimation of VI working capacity in extension of service life of WWER-1000 reactor.

1. Makhnenko, O.V., Mirzov, I.V. (2013) Investigation of stress-strain state of welded structures from austenitic steel at radioactive irradiation. The Paton Welding J., 1, 5-10.

2. Makhnenko, V.I., Makhnenko, O.V., Kozlitina, S.S. et al. (2012) Welded structures from austenitic steel of 10Kh18N10T type under conditions of radiation-induced swelling. Ibid., 2, 6-10.

3. Sorokin, A.A., Margolin, B.Z., Kursevich, I.P. et al. (2011) Influence of neutron irradiation on mechanical properties of materials of in-vessel internals of WWER type reactors. Voprosy Materialovedeniya, 2, 131-151.

4. Margolin, B.Z., Murashova, A.I., Neustroev, V.S. (2012) Analysis of influence of strained state type on radiation swelling and radiation creep of austenitic steels. Problemy Prochnosti, 3, 5-24.

Received 13.02.2014 